\title{
Bioavailability of Nickel (Ni) in Spiked Soils by Sequential Extraction and Its Bioaccumulation in Basil (Ocimum Africanum L)
}

\author{
Nopja A.R ${ }^{1}$, Asep Saefumillah ${ }^{2}$, Askal Maimulyanti ${ }^{3}$ \\ \{nopjaar.ui@gmail.com ${ }^{1}$, asep.saefumillah@sci.ui.ac.id ${ }^{2}$, askal_m@yahoo.com ${ }^{3}$ \} \\ University of Indonesia ${ }^{1,2}$, AKA Bogor Polytechnic ${ }^{3}$
}

\begin{abstract}
Soil samples are extracted by sequential extraction to assess metal speciation and its bioavailability, and each fraction will be tested with an AAS instrument. The bioavailability of spiked soil with $\mathrm{Ni}$ metal showed the most distribution detected in fraction 3 (bound to $\mathrm{Fe}$ and Mn Oxides) were percentage 38-58\%. Basil (Ocimum Africanum L) plants, which will be the media for the mobilization study of heavy metals, then plant were wet destruction and detected by ICP-MS. Furthermore, the ability of Basil to absorb Nickel showed a higher accumulation detected in roots, followed by stems and leaves (C-roots $>\mathrm{C}$-stems $>\mathrm{C}$-leaves). And different concentrations, it is known that the higher the concentration of metal spiked into the soil, the higher the concentration of nickel-metal that can be absorbed and detected in soil and plants. So, Basil able to hyperaccumulator nickel but low, cause $\mathrm{TF}<1$ and $\mathrm{BCF}<2$.
\end{abstract}

Keywords: Bioavailability; Nickel; Plant; Soil; Sequential Extraction

\section{Introduction}

Heavy metals are a group of metal elements that are categorized as dangerous if they enter the body of living things. Metals such as mercury $(\mathrm{Hg})$, chromium $(\mathrm{Cr})$, nickel $(\mathrm{Ni})$, zinc $(/ \mathrm{Zn})$, cadmium $(\mathrm{Cd})$, and lead $(\mathrm{Pb})$ can be found in aquatic environments contaminated with waste [1]. Since they appear to bioaccumulate, heavy metals are toxic. Compared with the concentration of a chemical in the atmosphere, bioaccumulation means a rise in the concentration of a chemical in a biological organism over time. Nickel is used in a variety of commercial and industrial applications, such as: steel armor (stainless steel), copper shielding, battery industry, electronics, aircraft industrial applications, textile industry, gas-fired power generation turbines, strong magnet makers, manufacturing laboratory equipment nichrome), electric light wires, fat catalysts, agricultural fertilizers, and various other functions [2]. Plants are known to accumulate Nickel so that when consumed it is transferred to the human body. In small amounts, Nickel is an essential element, but when it is in too high a concentration it is harmful to human health. Large amounts of nickel exposure will have the consequence of a higher likelihood of developing lung cancer, nose cancer, laryngeal cancer, and prostate cancer.

Bioavailability of heavy metals (nickel) means that the absorption of heavy metals by plants is controlled by various soil and biological factors [3]. Many factors that influence the bioavailability of $\mathrm{Ni}$ in soil include soil $\mathrm{pH}$, interaction with other metals, water holding capacity (WHC), cation exchange capacity (CEC), and organic matter (OM). pH (degree of 
acidity) is used to express the level of acidity or alkalinity of a solution. The water holding capacity represents the greatest amount of water the soil can hold against gravitational attraction. Cation Exchange Capacity is the total number of cations that can be exchanged on the colloid surface which is negatively charged which is closely related to the availability of nutrients for plants and is an indicator of soil fertility. The amount CEC is influenced by soil texture, clay mineral type, and material content. Total organic carbon (TOC) is the amount of carbon bound in the form of organic material. This soil organic material can be obtained from decomposing plants and animals, microorganisms, and soil biota. The absorption of a heavy metal by plants from heavily polluted soil is less than the absorption from lightly polluted soil. This is related to a higher $\mathrm{pH}$ increase by more pollutants and in line with the higher KPK, so that soil absorption becomes stronger.

Many researches related to metal speciation have been carried out, however, especially for metals in the soil, they are still limited [4]. The research was carried out using a gradual extraction method to determine the distribution and mobility of heavy metals in different soil compartments, in order to assess the consistency of urban and suburban soils irrigated by metal-enriched water in the city of Fez (Morocco). It can be seen from the results of these studies that $\mathrm{Cr}, \mathrm{Cu}, \mathrm{Ni}$ and $\mathrm{Pb}$ are mostly related to the residual fraction, so they only move a little in theory; while $\mathrm{Zn}$ is basically related to the metal oxide fraction and interchangeable phase in the soil, so $\mathrm{Zn}$ has the potential to move. Conducted a study to determine the chemical speciation of three heavy metals using a stepwise extraction method adapted from the protocol suggested by European Standards (SM\&T). The objective of this study was to determine the geochemical speciation of four metal boundaries: acid soluble, reducible, oxidized and residual, and to evaluate their effect on Banten Bay, Indonesia, sediments. The findings showed that in the residual fraction of the overall concentration, the proportion of copper (45.90-83.75 percent), nickel (18.28-65.66 percent), and zinc (30.45-79.51 percent) was mainly accumulated [5].

The urgency of this study is to focus on the problem of the risk of heavy metal contamination on agricultural land using polluted river water as irrigation. The risk of heavy metal contamination that accumulates in the soil and even gets absorbed into food plants (in this study is Basil) is the research concentration. A method that is effective, simple, and can provide information on the speciation of accumulated metal is also considered, so a sequential extraction method is chosen. In this study Ocimum Africanum L used to know ability as a Ni metal hyperaccumulator.

\section{Material and Methods}

\subsection{Chemical}

Nickel (II) sulphate hexahydrate (NiSO4. 6H2O) (Meck), Pottasium chloride (Meck), Nictric acid 65\% (Meck), Perchloric acid (Meck), Calcium Chloride (Meck), Hydrochloric Acid (Meck), Hydroxylammonium Chloride (Meck), Sodium Acetate (Meck), Acetic Acid (Meck), Hydrogen Peroxide (Meck), Aqua Regia (HCl : HNO3, 3:1), and Aquadest.

\subsection{Sampling Collected}

Soil samples were collected from farm in Rawa Kalong Village, Grogol, Depok, West Java in January 2020. Based on the observation of coordinate points through the Google Maps 
application, this location is at position 6'22'41 "S 106'47'30" E (latitude position 6 degrees 22 minutes 41 seconds and longitude position 106 degrees 47 minutes 30 seconds). The irrigation source used is river water around the rice fields. Soil is taken that is with a height of $0-30 \mathrm{~cm}$ from the ground.

\subsection{Characterization of Soil}

Characterization of original soil samples consisting of measurement of water content, $\mathrm{pH}$, total organic carbon (TOC), katon exchange capacity (CEC), soil texture, water holding capacity (WHC) and total Ni and Zn metals.

\subsection{Sequential Extraction}

In soils, the presence of metals can take different forms and bonds, including free ions and carbonate bonds, in which the metal in this form is considered a very unstable metal, such that it can be easily released into the waters and easily consumed by animals. When the metal binds to Fe / Mn oxide, the reduced form is (reducible). Metals are derived from this method of binding with organic matter and sulfides in an oxidizable form (oxidizable). In the form of a powerful bond with the mineral crystal structure in the soil, the residual form is meta [6]. The choice of reagent is related to the metal in the environment, the chemical properties of the metal, the matrix content of the sample to be extracted and the analytical technical availability in the laboratory. The procedure used for the five fractions based on Tessier, 1979 [7]. In this study, original (non-spike) soil samples and metal-spiked soil samples were used. In metalspike soils, the spike dose is $\mathrm{mg} \mathrm{kg}^{-1}$ of metal soil (ppm of soil).

\subsection{Plant growth experiment}

In this study, Basil will be planted in soil that has been controlled $(\mathrm{Nc})$ and contaminated by $\mathrm{Ni}$ with concentrations of $50(\mathrm{~N}-50), 200(\mathrm{~N}-200)$ and $400(\mathrm{~N}-400)$ ppm of soil. Air-dry soil samples that were clean from the rest of the roots, gravel and fine $(2 \mathrm{~mm})$ were weighed $200 \mathrm{~g}$ for each pot. Then the $\mathrm{Ni}$ and $\mathrm{Zn}$ solutions are added according to the desired treatment, then incubated for 20 days before planting to allow the metal to be evenly absorbed in the soil. In addition, non-spike ground is also used as control. Basil plant seeds are sown first in trays containing non-spike soil, before transplanting them into pots, transferring is done until the seeds grow leaves and are strong enough for 7-10 days. After that, planting 2 basil for each pot is carried out. Existing plants are maintained until vegetative growth for 5 weeks at a temperature of $30-32^{\circ} \mathrm{C}$ with daily sun exposure \pm 10 hours, during growth, $\pm 20 \mathrm{~mL}$ of demineralized water is watered. At harvest time the plants are cut about $1 \mathrm{~cm}$ above the ground using scissors. After that the plants are rinsed several times with demineralized water to remove soil particles. Subsequently, it was heated at $80^{\circ} \mathrm{C}$ for \pm 2 days until the water content remained. To calculate the metal content absorbed in the basil plant, the Basil is digested using the wet digestion method.

\subsection{Sample Pre-treatment (Wet aghig)}

As much as possible ( $\mathrm{g}$ ) of the dried basil sample is divided into 3 parts, namely the roots, stems and leaves, which have previously been crushed are put into a small beaker and weighed 
respectively, then added with $5 \mathrm{~mL}$ of concentrated $\mathrm{HNO}_{3}$ and let stand overnight. After that, heat it in a hotplate at $100^{\circ} \mathrm{C}$ for 1 hour 30 minutes, then cool it. Then added $5 \mathrm{ml}$ of concentrated $\mathrm{HNO}_{3}$ and $1 \mathrm{~mL}$ of $70 \% \mathrm{HClO}_{4}$. Reheat $\left( \pm 130^{\circ} \mathrm{C}\right)$ for 1 hour, the temperature is increased again to $150^{\circ} \mathrm{C}$ for 2 hours 30 minutes until the solution evaporates (yellow vapor runs out). After that, the temperature was increased to $170^{\circ} \mathrm{C}$ for 1 hour, and $200^{\circ} \mathrm{C}$ for 1 hour until white steam was formed and the volume was reduced (2-3 mL). Filter the solution into a $25 \mathrm{~mL}$ flask using filter paper. Wipe and dilute the filter paper to mark the boundaries. Then the solution is ready to be analyzed to determine the metal content with AAS.

\subsection{Instrumental \& Data Analysis}

The instrument used for initial characterization and sequential extraction was Atomic Absorption Spectrophotometry (AAS) type Shimadzu AA-6300, while for plant analysis using ICP-MS type Nex Ion 300 Perkin Elmer. The detection limits of nickel heavy metal in AAS and ICP-MS were $0.02 \mathrm{mg} / \mathrm{L}$ and $0.0037 \mu \mathrm{g} / \mathrm{mL}$ respectively. In order to determine the capacity of Acium Africanum, the Translocation Factor was determined and this ratio is an indicator of the plant's ability to translocate heavy metal from the roots to the aerial parts of the plant. TF values $<1$ are used to denote the accumulated heavy metal in plants and the lager contained in plant roots [8].

$\mathrm{TF}=\underline{\text { Heavy metal concentration in steam or leaf }}$

Heavy metal concentration in root

The amount of heavy metal from soil absorbed by plants was determined by the Bioconcentration Factor (BCF). Calculated by using the formula [9] :

$\mathrm{BCF}=\underline{\text { Metal concentration in whole-plant tissue }}$

Original concentration of metal in soil

The $\mathrm{BCF}$ values $>2$ were considered to be high values for the capacity of the plant to accumulate a specific metal in relation to its soil concentration [10].

Using Windows Excel, data on this analysis has been tabulated and is present in the table and map.

\section{Results and Discussions}

\subsection{Initial Soil Characterization}

The results of in situ measurement of the physical properties of soil samples which include sample water content, soil texture, soil $\mathrm{pH}\left(\mathrm{pH} \mathrm{H}_{2} \mathrm{O}\right.$ and $\left.\mathrm{pH} \mathrm{KCl}\right)$, organic carbon, water holding capacity (WHC), and cation exchange capacity (CEC) were obtained. as follows:

Table 1. Soil Characterization Test Results

\begin{tabular}{ll}
\hline Parameter (Unit) & Results \\
\hline Ground water content $(\%)$ & 19,43 \\
$\mathrm{pH} \mathrm{H} \mathrm{H}_{2} \mathrm{O}$ & 4,4 \\
$\mathrm{pH} \mathrm{KCl}$ & 3,7 \\
Soil texture (\%) & \\
$\quad-\quad$ Dust & 1,33
\end{tabular}




\begin{tabular}{cl}
$-\quad$ Sand & 37,33 \\
$-\quad$ Clay & 61,33 \\
Organic Carbon Content (\%) & 1,44 \\
Water Holding Capacity $(\%)$ & 82 \\
Cation Exchange Capacity $\left(\mathrm{C} \mathrm{mol}^{+} / \mathrm{kg}\right)$ & 20,98 \\
\hline
\end{tabular}

Soil characterization experiments in the table above were carried out to determine the initial chemical properties of the sample before being given treatment. The water resistance capacity can reach $82 \%$ or $82 \mathrm{~mL} / 100 \mathrm{~g}$ of soil and water content of $19.43 \%$. The composition of the soil sample consisted of $1.33 \%$ dust textured, $37.33 \%$ sand textured and $61.33 \%$ clay textured. This shows that the soil sample is classified as fine texture. Soil texture has a relationship with water holding power and nutrient availability. According to Hardjowigeno [11], water is contained in the soil because it is absorbed (retained) by the soil mass, is held back by an impermeable layer, or because of poor drainage conditions. Soil samples are slightly acidic containing a pH of $4.4 \mathrm{H}_{2} \mathrm{O}$ and a $\mathrm{pH}$ of $3.7 \mathrm{KCl}$. $\mathrm{pH}$ of $\mathrm{KCl}$ is the potential acidity obtained from the interaction of $\mathrm{KCl}$ with organic compounds in the soil. The soil sample used has a cation exchange capacity (CEC) of $20.98 \mathrm{cmol}^{+} / \mathrm{kg}$. This value is large enough for the soil to exchange cations. Soil acidity can cause problems such as decreasing nutrient availability for plants, increasing the impact of toxic elements and decreasing crop yields. The sample's organic $\mathrm{C}$ content was $1.44 \%$. Organic material from the soil is $1.44 \%$ of the total soil weight.

\subsection{Mobility and bioavailability of $\mathrm{Ni}$ in soils}

Ni metals were spiked into $10 \mathrm{~g}$ soil with different concentrations of $100 \%$ WHC. Then $2 \mathrm{~g}$ each is taken and put into a centrifuge tube for gradual extraction consisting of 5 fractions. The reagent used was adjusted by the Teasser method and modified with the reagent from the half-reaction method [12].

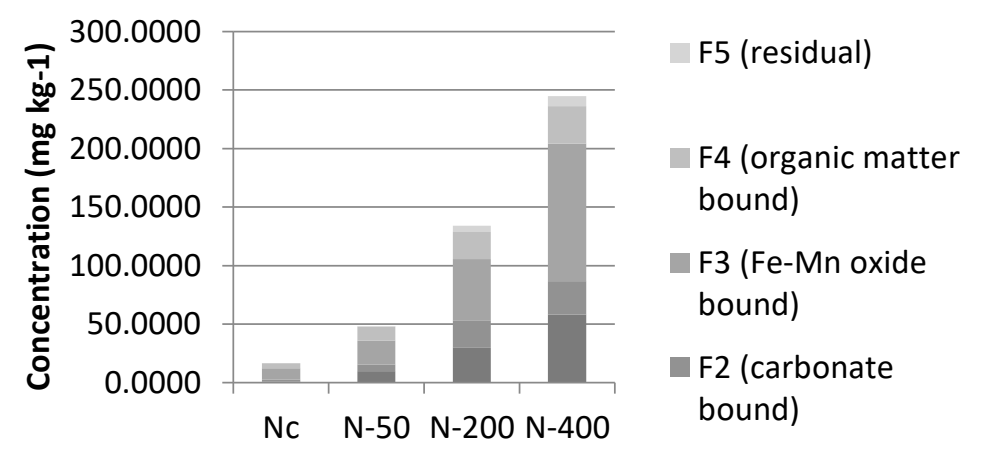

Fig. 1. Concentration Ni among steps in extraction of soil samples

The control soil (untreated) obtained the residual (F5) fractions below the detection limit, while at most in Fe/Mn oxide (F3) and organic matter (F4) fractions, respectively. In Ni metal, the species binds to Fe/Mn oxide is the fraction that is mostly found in $\mathrm{Ni}$ metal amounting to $9-117 \pm 0.03-0.45 \mathrm{mg} \mathrm{kg}^{-1}$ (Fig.1). Next is the organic matter fraction. This is indeed common, since oxides account for a large proportion of the total soil weight [13]. $\mathrm{Fe}$ Mn Oxide is the most important metal adsorbent in the soil. 


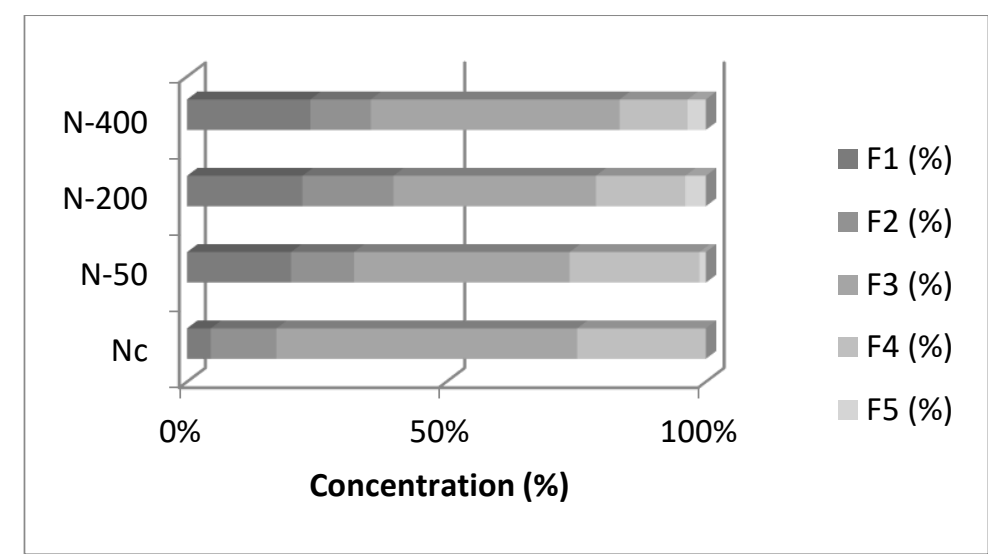

Fig. 2. The partitioning of Ni among steps in sequential extraction of sample soil

Fig. 2 shows the extracted percentages of $\mathrm{Ni}$ in all steps of the extraction procedures of soil sample. The higest percentages of Nickel in Fe-Mn Oxide fractions were found to be in range $38-58 \%$. The higher the nickel concentration in the spike, the higher the bioavailability of Nickel in the soil for any fraction or total Nickel in the soil.

\subsection{Accumulation of Ni from soil to Basil}

After each crop was harvested at a certain time, namely the 24-30th day for control soil and Ni spike. Samples were wet digestion with concentrated acid and analyzed using ICP-MS.

Table 2. Concentration and Acumulation on Leaf

\begin{tabular}{cccc}
\hline Sample & Biomas $(\mathbf{g D W})$ & Concentration $\left(\mathbf{m g ~ k g}^{-\mathbf{1}}\right)$ & Accumulation $(\mu \mathrm{g})$ \\
\hline $\mathrm{Nc}$ & 0.3270 & LLD & LLD \\
N-50 & 0.3140 & 0.4191 & 0.1316 \\
N-200 & 0.0930 & 5.2667 & 0.4898 \\
N-400 & 0.0300 & 23.6200 & 0.7086 \\
\hline
\end{tabular}

To determine biomass and nickel accumulation, leaf concentrations were used. Table 2 indicates the concentration and aggregation in the soil culture of plant leaves at various $\mathrm{Ni}$ concentrations. The accumulation of $\mathrm{Ni}$ in leaves increased with rising levels of $\mathrm{Ni}$ spikes. And with increasing solution concentrations of $\mathrm{Ni}$, leaf biomass decreased. The highest accumulation of $\mathrm{Ni}$ in leaves was $0.7086 \mu \mathrm{g}$ at the $400 \mathrm{mg} \mathrm{kg}^{-1} \mathrm{Ni}$ spike concentration. 


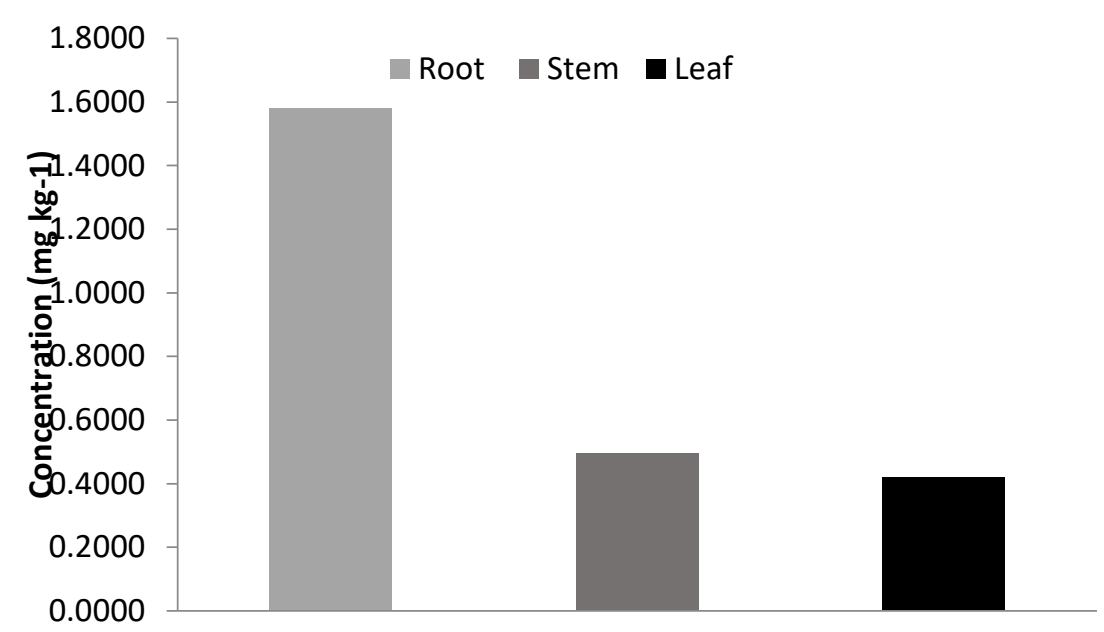

Fig. 3. Nickel in Plant Parts

From the results of the ICP-MS data obtained, it was found that the Ni metal was mostly in the roots, stems and leaves. The highest Ni concentraton and accumulation in root were 1.58 mg.kg-1 (Fig.3). The results show that Ocimum Africanum Lour has a low potential for biomass and $\mathrm{Ni}$-accumulation in soil that is contaminated by heavy metals.

Table 3. Translocation Factor (TF) and Bioaccumulation Factor (BCF)

\begin{tabular}{llllll}
\hline Ni spike & TF & \multicolumn{3}{c}{ BCF } \\
\cline { 2 - 6 } & Root-Stem & Root-Leaf & Root & Stem & Leaf \\
$\mathbf{5 0 ~} \mathbf{~ m g ~ k g}^{-1}$ & 0.3131 & 0.2653 & 0.0316 & 0.0099 & 0.0084 \\
\hline
\end{tabular}

The ability to accumulate high concentrations of metal or metalloids in the aboveground biomass is a translocation factor (TF) and bioconcentration factor (BCF) that provide two characteristics of hyperaccumulator plates. Usually, the translocation factor (TF) for hyperaccumulator plants is $>1$. In Ocimum Africanum L, translocation factors for Ni were found to be in the range of 0.2-0.3 (Table 3). Bioaccumulator factor of Ni heavy metals in basil show $\mathrm{BCF}<2$ in all parts of plant, which is equal to $0.008-0.03$. The mechanism by which plants acquire metal ions in the soil is usually influenced by the three basic processes of mass flow, diffusion, and root interception [14].

Based on the research results, it can be seen that the increase in nickel concentration spiked in the soil is directly proportional to the total biovailability of heavy metal nickel in the soil and plant bioaccumulation. Which means that the higher the $\mathrm{mg} \mathrm{kg}^{-1}$ of Nickel in the soil, the higher the bioavailability in the soil in the form of 5 fractions and its absorption in plant parts. 


\section{Conclusion}

In order to determine the mobility and chemical types of $\mathrm{Ni}$ in soil samples, different selective chemical reagents and the five sequential extraction procedures used in this study were found to be useful. The concentration and percentages of Nickel up to $58 \%$ in Fe-Mn Oxide fractions. This makes nickel metal bioavailable and mobile from the soil to the basil plant. It was concluded that Ocimum Africanum L plant showed $\mathrm{TF}$ and $\mathrm{BCF}$ value low hyperaccumulator, but ocimum Africanum potential as Nickel (Ni) bioacumulators.

Acknowledgments. This study was funded by Kementerian Riset dan TeknologiSimblitabmas 2.0 period 2020 with contract no. NKB-486/UN2.RST/HKP.05.00/2020.

\section{Reference}

[1] Nugroho, A. 2006. Bioindikator Kualitas Air. Universitas Trisakti. Jakarta

[2] [Gerberding J.L.2005. Toxicological Profile for Nickel, Atlanta, Georgia, Agemcy for Toxic Subtances and Disease Registry. Division of Toxicology.

[3] Verloo, M.G., \& Hendrickx, F. (2002). Heavy metal contents (Cd, Cu Zn) in spiders (Pirata piraticus) living in intertidal sediments of the river Scheldt estuary (Belgium) as affected by substrate characteristics. Sci. Total Environ. 289(1-3): 71-81.

[4] Bellarbi, M. and Nuclear Techniques. 2018. "Speciation of $\mathrm{Cr}, \mathrm{Cu}, \mathrm{Ni}$ and $\mathrm{Zn}$ in Soils Irrigated with Contaminated Waters: A Case Study of Agricultural Soils from the Plain of Saiss (Fez, Morocco).

[5] Lestari, Tri \& Khairunnisa. 2017. Partisi Geokimiawi Logam Berat Cu dan Zn dalam Sedimen di Perairan Teluk Banten, Banten. Bogor : IPB

[6] Yu, X., Y. Yana, and W. Wang, 2010, The Distribution and Speciation of Trace Metals in Surface Sediments from The Pearl River Estuary and The Daya Bay, Southern China, Marine Pollution Bulletin, 60 : 1364-1371

[7] Tessier, A., Campbell, P.G.C. and Bisson, M. 1979. Sequential Extraction Procedure for the Speciation of Particulate Trace Metals. Analytical Chemistry, 51, 844-851

[8] Mellem, J.J., Baijnath, H., Odhav, B. 2012. Bioaccumulation of $\mathrm{Cr}, \mathrm{Hg}$, $\mathrm{As}, \mathrm{Pb}, \mathrm{Cu}$ and $\mathrm{Ni}$ with ability for hyperaccumulation by Amaranthus dubius. Africanum Journal of Agricultural Research. 7(4): 591-596

[9] Ghosh M, Sing SP. 2005. A comparative study of cadmium phytoextraction by accumulator and weed species. Environ. Poll., $133: 365-371$

[10] Mellem, J.J., Baijnath, H., Odhav, B. 2012. Bioaccumulation of $\mathrm{Cr}, \mathrm{Hg}$, As, $\mathrm{Pb}, \mathrm{Cu}$ and $\mathrm{Ni}$ with ability for hyperaccumulation by Amaranthus dubius. Africanum Journal of Agricultural Research. 7(4): 591-596

[11] Hardjowigeno, Sarwono Frof Dr. Ir. H. M,Sc. 2003. Klasifikasi Tanah dan Phetagonesis Akademika Presindo: Jakarta.

[12] Jo A. Zimmerman., \& David C. Weindorf. 2010. Heavy metal and trace metal analysis in soil by sequential extraction : A review of procedures. International Journal of Analytical Chemistry

[13] Filgueiras A. V., Lavilla I. \& Bendicho C. 2002. Chemical Sequental Extraction for Metal Partioning in Enviromental Solid Samples. Journal of Environ. Monit. 4, 823-857

[14] Agbenin, John O. and Gerhard Welp. 2012. "Bioavailability of Copper , Cadmium , Zinc , and Lead in Tropical Savanna Soils Assessed by Diffusive Gradient in Thin Films ( DGT ) and Ion Exchange Resin Membranes.” 2275-84. 